\title{
Steps solidifying a role for SEPT9 in breast cancer suggest that greater strides are needed
}

\author{
Laura Stanbery ${ }^{1 *}$ and Elizabeth M Petty ${ }^{2}$ \\ See related research by Connolly et al., http://breast-cancer-research.com/content/13/4/R76
}

\begin{abstract}
Septins comprise a conserved family of GTPase proteins. Of these, human SEPT9 has been widely implicated in cancers of epithelial origin, including breast cancer, as well as leukemia. In a previous issue of Breast Cancer Research, Connolly and colleagues present compelling data further supporting a role for SEPT9 isoforms in early breast cancer development as well as evidence suggesting that cellular localization patterns of SEPT9 isoforms may contribute to oncogenesis.
\end{abstract}

Connolly and colleagues [1] help substantiate that septins, proteins proven critical for normal cell division [2], are relevant to cancer. The 13 septin loci identified in humans [3] have been associated with important cellular functions, from angiogenesis to vesicular trafficking, and a wide variety of human diseases, from cancer to neurological conditions (reviewed in [4-6]). SEPT9 was identified as a myeloid/lymphoid leukemia (MLL) fusion partner in leukemia [7] and cloned from a region of allelic imbalance in breast and ovarian cancers $[8,9]$. The SEPT 9 locus is complex. It encodes at least five different protein isoforms that form oligomeric complexes with other septins $[10,11]$. SEPT9 isoforms share core domains, including a GTPase domain with a putative nuclear localization signal, but differ at the amino and carboxyl termini (reviewed in $[3,4]$ ). Altered expression of SEPT9 and its variant isoforms have been implicated in breast, ovarian, prostate, colon, and head and neck cancers [5,12-16] whereas SEPT9 mutations have been associated with hereditary neuralgic amyotrophy [17]. SEPT9

\footnotetext{
*Correspondence: nejedlik@umich.edu

'University of Michigan Medical School, Department of Internal Medicine-

Hematology/Oncology, 7111 Comprehensive Cancer Center, Ann Arbor, MI 48109, USA

Full list of author information is available at the end of the article
}

research has focused on differential expression levels of SEPT9 in malignant and non-malignant cells, cellular responses to differing expression of SEPT9 isoforms, and characterization of interacting proteins, including other septins, and associated molecular pathways, such as hypoxia inducibe factor-1 alpha and JNK signaling $[14,18,19]$. SEPT9_i1, an isoform implicated as an oncogene [12-14], differs by 25 unique amino-terminus amino acids, including an additional nuclear localization signal. High ectopic SEPT9_i1 expression in immortalized human mammary epithelial cells leads to oncogenic phenotypes and increased SEPT9_i1 nuclear localization [12]. Knock-down of SEPT9_i1 expression in cancer cells normalizes oncogenic phenotypes [12,18]. High SEPT9 expression also leads to cytokinesis and chromosome segregation defects [20-22].

Connolly and colleagues [1] present compelling evidence confirming SEPT9 amplification and high SEPT9 expression in breast cancer cells [12,23]. They found increased Sept9 levels in hyperplastic and malignant stages. They noted SEPT9_i1, as well as SEPT9 _i3, _i4, and _i5, increased cell migration in MCF7 cells, substantiating a potential role for SEPT9_i1 and other SEPT9 isoforms as putative oncogenes in breast cancer. Mechanisms regulating SEPT9 isoform expression and contributing to tumorigenesis remain unclear. They did find that SEPT9_i3 has a unique promoter that is hypermethylated in many breast cancer cells [1]. While overall SEPT9 and SEPT9_i1 expression was often high in cancer cells, SEPT9_i3 expression was often low. In some breast cancer cell lines, however, SEPT9_i3 promoter hypomethylation with high SEPT9_i3 expression was noted and green fluorescent protein (GFP)-SEPT9_i3 expression in MCF7 cells increased migration [1]. Thus, the role of SEPT9_i3 promoter methylation in breast cancer remains unclear but hypermethylation and decreased SEPT9 expression has been reported in colon cancer and head and neck cancer $[15,16,24]$. More recent data in head and neck cancer, however, suggest high SEPT9 and SEPT9_i1 expression is associated with later cancer stages and poor outcomes, supporting oncogenic roles [13]. Given SEPT9 isoforms interact in oligomeric 
complexes, it is plausible that altered ratios of SEPT9 isoforms, where high levels of one, such as SEPT9_i1, and low levels of another, such as SEPT9_i3, may be important in tumorigenesis. Further studies are required to determine if changes in interactions between septin isoforms can impact tumorigenesis.

Previous studies suggest that SEPT9 is generally cytoplasmic, often as filamentous structures, or within contractile rings of dividing cells. Diffuse cytoplasmic localization and nuclear localization have also been observed $[12,20]$. Connolly and colleagues provide novel, intriguing evidence that cellular localization of SEPT9 isoforms may be relevant to cancer [1]. They found characteristic cytoplasmic SEPT9 staining in all cells as well as nucleolus localization in human and murine luminal breast epithelial cells. Nuclear localization was lost in more advanced tumor cells. They also noted differences in the organization of SEPT9 filaments in the nucleus and cytoplasm when different GFP-SEPT9 isoforms were expressed in MCF7 cells. While functional roles of septins can be associated with their cytoplasmic localization, the role of SEPT9 isoforms in the nucleus is less clear, although SEPT9_i1 stabilization of JNK may be a nuclear associated function [19]. Previous studies postulated increased SEPT9 nuclear localization in breast cancer [12], but immortalized cells may not mimic physiologic conditions in mammary glands. Specific antibodies used and fixation methods employed may also contribute to differing results of localization studies. Thus, additional studies to examine cellular localization of SEPT9 and the impact this has on cellular functions and cancer progression are needed. Future studies of live primary cells using GFP-tagged SEPT9 constructs may be informative.

\section{Conclusion}

The work by Connolly and colleagues [1] provides additional significant support for the roles of SEPT9 isoforms in cancer. Importantly, their studies in human breast tissue microarrays and cells from a mouse model of breast cancer support early SEPT9 involvement in mammary tumorigenesis. Furthermore, they provide evidence that suggests that cellular localization of SEPT9 isoforms may be important in cancer development. Many unanswered questions remain regarding the clinical relevance of SEPT9 expression patterns in breast cancer and about the molecular mechanisms by which SEPT9 isoforms contribute to the pathogenesis of cancer. Further correlation of tissue expression with clinicopathological variables is essential to help determine clinical relevance to breast cancer. Additional functional studies of SEPT9 isoforms are required to begin understanding molecular mechanisms important in normal cellular functions, mammary gland development, and the pathogenesis of breast cancer. A better understanding of the cellular functions and clinical correlations of SEPT9 isoforms relevant to cancer could provide valuable insights into future diagnostic, prognostic and therapeutic strategies important in the management of breast cancer. For now, the intriguing findings of Connelly and colleagues [1], as well as other published findings implicating SEPT9 in cancer, translate into a compelling rationale for more intensive studies of septins in cancer.

\section{Abbreviations}

GFP, green fluorescent protein.

\section{Competing interests}

The authors declare that they have no competing interests.

\section{Author details}

'University of Michigan Medical School, Department of Internal MedicineHematology/Oncology, 7111 Comprehensive Cancer Center, Ann Arbor, M! 48109, USA. ${ }^{2}$ University of Wisconsin School of Medicine and Public Health, 4121 Health Sciences Learning Center, 750 Highland Ave, Madison, WI 53705, USA.

Published: 9 January 2012

\section{References}

1. Connolly D, Yang Z, Castaldi M, Simmons N, Oktay MH, Coniglio S, Fazzari MJ, Verdier-Pinard P, Montagna C: Septin 9 isoform expression, localization and epigenetic changes during human and mouse breast cancer progression. Breast Cancer Res 2011, 13:R76.

2. Hartwell LH: Genetic control of the cell division cycle in yeast. IV. Genes controlling bud emergence and cytokinesis. Exp Cell Res 1971, 69:265-276.

3. Russell SEH, Hall PA: Septin genomics: a road less travelled. Biol Chem 2011, 392:763-767.

4. Peterson EA, Petty EM: Conquering the complex world of human septins: implications for health and disease. Clin Genet 2010, 77:511-524.

5. Connolly D, Abdesselam I, Verdier-Pinard P, Montagna C: Septin roles in tumorigenesis. Biol Chem 2011, 392:725-738.

6. Roeseler S, Sandrock K, Bartsch I, Zieger B: Septins, a novel group of GTP-binding proteins: relevance in hemostasis, neuropathology and oncogenesis. Klin Padiatr 2009, 221:150-155.

7. Osaka M, Rowley JD, Zeleznik-Le NJ: MSF (MLL septin-like fusion), a fusion partner gene of $M L L$, in a therapy-related acute myeloid leukemia with a $\mathrm{t}(11 ; 17)$ (q23;q25). Proc Natl Acad Sci U S A 1999, 96:6428-6433.

8. Kalikin LM, Sims HL, Petty EM: Genomic and expression analyses of alternatively spliced transcripts of the MLL septin-like fusion gene (MSF) that map to a 17q25 region of loss in breast and ovarian tumors. Genomics 2000, 63:165-172.

9. Russell SE, Mcllhatton MA, Burrows JF, Donaghy PG, Chanduloy S, Petty EM, Kalikin LM, Church SW, Mcllroy S, Harkin DP, Keilty GW, Cranston AN, Weissenbach J, Hickey I, Johnston PG: Isolation and mapping of a human septin gene to a region on chromosome $17 q$, commonly deleted in sporadic epithelial ovarian tumors. Cancer Res 2000, 60:4729-4734.

10. Sandrock K, Bartsch I, Busse A, Busse E, Zieger B: Characterization of human septin interactions. Biol Chem 2011, 392:751-761.

11. Peterson EA, Kalikin LM, Steels JD, Estey MP, Trimble WS, Petty EM: Characterization of a SEPT9 interacting protein, SEPT14, a novel testisspecific septin. Mamm Genome 2007, 18:796-807.

12. Gonzalez ME, Peterson EA, Privette LM, Loffreda-Wren JL, Kalikin LM, Petty EM: High SEPT9_v1 expression in human breast cancer cells is associated with oncogenic phenotypes. Cancer Res 2007, 67:8554-8564.

13. Stanbery L, D'Silva NJ, Lee JS, Bradford CR, Carey TE, Prince ME, Wolf GT, Worden FP, Cordell KG, Petty EM: High SEPT9_v1 expression is associated with poor clinical outcomes in head and neck squamous cell carcinoma. Transl Oncol 2010, 3:239-245.

14. Amir S, Wang R, Matzkin H, Simons JW, Mabjeesh NJ: MSF-A interacts with hypoxia-inducible factor-1alpha and augments hypoxia-inducible factor transcriptional activation to affect tumorigenicity and angiogenesis. 
Cancer Res 2006, 66:856-866.

15. Bennett KL, Romigh T, Eng C: Disruption of transforming growth factorbeta signaling by five frequently methylated genes leads to head and neck squamous cell carcinoma pathogenesis. Cancer Res 2009, 69:9301-9305

16. Toth K, Galamb O, Spisak S, Wichmann B, Sipos F, Valcz G, Leiszter K, Molnar B, Tulassay Z: The influence of methylated septin 9 gene on RNA and protein level in colorectal cancer. Pathol Oncol Res 2011, 17:503-509.

17. Hannibal MC, Ruzzo EK, Miller LR, Betz B, Buchan JG, Knutzen DM, Barnett K, Landsverk ML, Brice A, LeGuern E, Bedford HM, Worrall BB, Lovitt S, Appel SH, Andermann E, Bird TD, Chance PF: SEPT9 gene sequencing analysis reveals recurrent mutations in hereditary neuralgic amyotrophy. Neurology 2009, 72:1755-1759

18. Amir S, Golan M, Mabjeesh NJ: Targeted knockdown of SEPT9_v1 inhibits tumor growth and angiogenesis of human prostate cancer cells concomitant with disruption of hypoxia-inducible factor-1 pathway. Mol Cancer Res 2010, 8:643-652.

19. Gonzalez ME, Makarova O, Peterson EA, Privette LM, Petty EM: Up-regulation of SEPT9_v1 stabilizes C-Jun-N-terminal kinase and contributes to its pro-proliferative activity in mammary epithelial cells. Cell Signal 2009, 21:477-487

20. Surka MC, Tsang CW, Trimble WS: The mammalian septin MSF localizes with microtubules and is required for completion of cytokinesis. Mol Biol Cell 2002, 13:3532-3545.

21. Estey MP, Di Ciano-Oliveira C, Froese CD, Bejide MT, Trimble WS: Distinct roles of septins in cytokinesis: SEPT9 mediates midbody abscission. J Cell Biol 2010, 191:741-749

22. Peterson EA, Stanbery L, Li C, Kocak H, Makarova O, Petty EM: SEPT9_i1 and genomic instability: Mechanistic insights and relevance to tumorigenesis. Genes Chromosomes Cancer 2011, 50:940-949.

23. Montagna C, Lyu MS, Hunter K, Lukes L, Lowther W, Repert T, Hissong B, Weaver Z, Reid T: The Septin 9 (MSF) gene is ampliofied and overexdpressed in mouse mammary gland ademocarcinomas and human breast cancer cell lines. Cancer Res 2003, 63:2179-2187.

24. deVos T, Tetzner R, Model F, Weiss G, Schuster M, Distler J, Steiger KV Grützmann R, Pilarsky C, Habermann JK, Fleshner PR, Oubre BM, Day R, Sledziewski AZ, Lofton-Day C: Circulating methylated SEPT9 DNA in plasma is a biomarker for colorectal cancer. Clin Chem 2009, 55:1337-1346.

doi:10.1186/bcr3056

Cite this article as: Stanbery L, Petty EM: Steps solidifying a role for SEPT9 in breast cancer suggest that greater strides are needed. Breast Cancer Research 2012, 14:101. 